\title{
The Role of Liposome -Encapsulated Ascorbic Acid on Hemoglobin Damage By Gamma Irradiation.
}

\author{
Aida A. Salama ${ }^{x}$; Mohammed H. Gaber ${ }^{\times x}$; Aziza A. EL Saeid ${ }^{\times}$; Basma Y.EL \\ Adawy $^{\times}$ \\ ${ }^{\times}$Physics Department ,Faculty of Science ,AL-Azhar university,Cairo, ${ }^{\times \times}$Biophysics \\ Department ,Faculty of Science, Cairo university, Giza,Egypt.
}

\begin{abstract}
ONIZING radiation causes serious damage in a biological system. Some drugs and antioxidants are used to prevent such damage. In vitro we study the effect of free ascorbic acid(AA) and liposome encapsulation ascorbic acid (LEAA) to prevent damage induced by gamma irridiatin on rats blood . Liposomes prepared by thin film hydration method . Size ,and poly dispersed index (PDI) were analyzed by dynamic light scattering before and after encapsulation AA , and shape was analyzed by transmission electron microscopy(TEM). Percentage encapsulation efficiency (EE\%) of ascorbic acid was determined and IR study has been employed to reveal structure alteration in vesicles before and after encapsulation. two doses of free ascorbic acid ( $20 \mu \mathrm{g} / \mathrm{ml}, 40 \mu \mathrm{g} / \mathrm{ml}$ ) were selected to be used for such purpose. Also the same doses were used encapsulated in liposomes . Our study were carried through UVvisible spectrum absorption spectrum, relative viscosity and conductivity measurement. The results show that $\mathrm{EE} \%$ have a high encapsulation of vitamins $\mathrm{C}$, there no detectable change is observed in size of liposome before and after encapsulation. The data obtained from UV-visible indicate that there is great change in the absorbance of sort band, and in the absorption A576/ A541 ratio in blood irradiated to $5 \mathrm{GY} \gamma$ - irradiation by dose rate $62 \mathrm{cGY} / \mathrm{mint}$ as compared with normal hemoglobin. The result indicated that the change decreases by increasing doses of free AA came close to normal hemoglobin and approaching more to normal in the case of liposome encapsulation ascorbic acid .
\end{abstract}

Keywords: liposome,Hemoglobin, $\gamma$-irradiation, Ascorbic acid, UV visible absorption spectra.

\section{Introduction}

Radiation produces numerous biological disturbance in cells by direct ionization of DNA and other cellular targets such as lipids and proteins, and by indirect effect through free radical production. Free radicals are highly reactive chemicals and can initiate a chain of events in the cell which will eventually lead to injury and even cell death Steel, (2002) . Due to water radiolysis, the most abundant intracellular compounds, various types of free radicals are generated such as hydroxyl radicals $\left(\mathrm{OH}^{\circ}\right)$, hydrogen radicals $\left(\mathrm{H}^{\circ}\right)$. In the presence of oxygen, reactive oxygen species (ROS) such as superoxide anion and hydrogen peroxide (H2O2) are also formed, leading to induction of more DNA damage and radiation cytotoxicity in the cells Hall ,2000).\& Laverne ,(2000).The $\mathrm{OH}^{\circ}$ free radicals is generally considered the most damaging of the oxygen-based free radicals and it is believed to account for an estimated $50 \%$ of the total damage induced by free radical mechanisms Imlay and Linn, (1988).

Vitamin C (ascorbic acid) has been reported to be an effective antioxidant and free radical scavenger. Both under in vitro and in vivo conditions, it reduces oxidative and free radical induced damages to DNA and membranes in biological systems Wilson, (1983). It functions as a free radical scavenger of active and stable oxygen radicals. Vitamin $\mathrm{C}$ has been shown to protect several biological systems against ionizing radiations. The radioprotective effect of ascorbate seems to be due to its interactions with 
radiation induced free radicals Duschesne et al. (1975). Ascorbic acid pre-treatment inhibited the radiation induced elevation in lipid peroxidation Jagetia, (2004). It protected mice against radiation induced sickness, mortality and improves the healing of wounds after exposure to whole body $\gamma$ radiation Mallikarjuna and Jagetia, (2004).

The aim of this study is to examine the damage of gamma radiation (at therapeutic doses) on the molecular properties of haemoglobin in vitro study and Comparing the radioprotection effect between free ascorbic acid and liposome encapsulating ascorbic acid.

\section{Materials and Methods}

In this study 64 female Swiss albino rats having weight ranged between $(80-100 \mathrm{~g})$ maintained at animal house laboratory, National Research Center under the normal conditions of water and diet supply, the blood come from the eyes into tube containing ethylenediamine tetraacetic acid ( EDTA) using capillary tubes.

The animals are divided to Control group (C) Normal blood and Irradiated groups which are divided to four subgroups. Every one composed of 5 rats.

Group A : included 5 blood samples exposed to $\gamma$-irradiation.

Group E: included 5 blood samples with liposomes $100 \mu \mathrm{g} / \mathrm{ml} 2 \mathrm{hr}$ before exposing to $\gamma$ -irradiation.

Group B: having sup groups B2and B3 Blood with different doses of free ascorbic acid solution $20 \mu \mathrm{g} / \mathrm{ml}$ and $40 \mu \mathrm{g} / \mathrm{ml}$ respectively $2 \mathrm{hr}$ before exposing to $\gamma$-irradiation.

Group D: having sup groups D2 and D3 Blood with different doses of LEAA solution $20 \mu \mathrm{g}$ LEAA $/ \mathrm{ml}$ and $40 \mu \mathrm{gLEAA} / \mathrm{ml}$ respectively $2 \mathrm{hr}$ before exposing to $\gamma$-irradiation.

Ascorbic acid powder (purity $>=99 \%$ ), molecular weight $176.124 \mathrm{~g} / \mathrm{mol}$ and Melting point $\left(190^{\circ} \mathrm{C}\right)$ from (Sigma Aldrich, Egypt) and 1,2 Dipalmitoyl-sn-glycero-3-phosphatidylcholine (DPPC) lipid is purchased from Avanti polar Lipids ( Alabaster, AL, USA).

Blood samples were exposed to 5Gy $\gamma$-irradiation with dose rate $62 \mathrm{cGY} /$ minute emitted from cobalt 60 in the Radiotherapy and Nuclear Medicine department, Al Hussein University Hospital , Al Azhar university.
Hemoglobin prepared according to Trivelli method as follow .The blood sample draining from the eyes into tube containing EDTA ,using capillary tubes, The heparinized blood was centrifuged at $3500 \mathrm{rpm}$ for 10 minutes at $24^{\circ} \mathrm{C}$, then the plasma was removed, the packed red blood cells were washed with 2 volumes of saline solution sodium chloride $(0.9 \% \mathrm{NaCl})$ at $24^{\circ} \mathrm{C}$ ,the mixture then recentrifuged at $3500 \mathrm{rpm}$ for 10 minutes to separate the washed red blood cells from the saline, repeated this process 3 times ,the washed packed red blood cells were lysed with two volumes of deionized water, and Kept overnight at $4{ }^{\circ} \mathrm{C}$ to insure lysis of the cells and liberation of the sap into suspension, the hemolysate was then centrifuged at $4000 \mathrm{rpm}$ for 45 minutes at $4{ }^{\circ} \mathrm{C}$ to remove erythrocyte ghosts. Trivelli et al. (1971), the clear hemoglobin separated and stored at $4{ }^{\circ} \mathrm{C}$ ready for measurements.

Liposome encapsulation ascorbic acid (LEAA) are prepared by thin film hydration method Vanaja et al. (2008) dry of phospholipids are dissolved in chloroform in around bottome flask, the organic solvent was evaporated under vacuum using a rotary evaporator (RE 300, Bibby Scientific, UK), rotated under vacuum at speed of $90 \mathrm{rpm}$ and a temperature above the lipid transition temperature $\left(51^{\circ} \mathrm{C}\right)$ to obtain a uniform thin film on the inner wall of the flask, the film is hydrated with normal saline NaCL 0.9 $\mathrm{w} / \mathrm{v} \%$ solution containing amount of ascorbic acid $(3 \mathrm{mg} / \mathrm{ml})$ at $51^{\circ} \mathrm{C}$ for $10 \mathrm{~min}$,multilamellar liposomes are formed by constant vortexing for $10 \mathrm{~min}$. The suspension is afterward sonicated in a water bath with pulses of $80-\mathrm{KHz}$ ultrasound and intensity of $0.04 \mathrm{~W} / \mathrm{cm}^{2}$ at $50 \pm 1$ for $15 \mathrm{~min}$ resulting in a large unilamellar vesicles (LUV) suspension Silva et al. (2010), the suspension is then ultra-centrifugedat $14000 \mathrm{rpm}$ at $4{ }^{\circ} \mathrm{C}$ for 50 min to separate the non-encapsulation AA from encapsulation AA.

Percentage encapsulation efficiency (\% EE) of AA was measured by the Kjeldahl method, as described before Liu et al. (2013) . Liposome solution was subjected to ultracentrifugation (Beckman L7 ultracentrifuge, Beckmann Coulter $\mathrm{GmbH}$ ) for $50 \mathrm{~min}$ at $14,000 \mathrm{rpm}$ at $4{ }^{\circ} \mathrm{C}$ and supernatant which contain the free ascorbic acid is analyses using HPLC to determine the amount of AA in supernatant solution . Percentage EE of vitamin $\mathrm{C}$ was determined indirectly from the free concentration in the supernatant after ultracentrifugation using reversed phase (Hight 
Performance liquid Chromatography) according to the equation Kall and Andersen ,(1999).

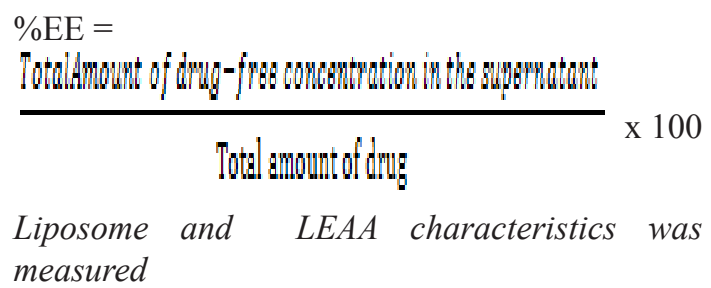

Size distribution analysis (Z-average mean size and polydispersity index) were determined by dynamic light scattering (DLS), using a nanosizer (Nano-ZS, Nanoseries, Malvern Instruments, UK) after appropriate dilution of liposome preparation Jagetia, (2004) which uses a $4 \mathrm{~mW}$ He-Ne laser operating at a wavelength of $633 \mathrm{~nm}$ and a detection angle of 173 . The viscosity of 0.8872 $\mathrm{mPas}$ and refractive index of 1.33 for deionized water at $25^{\circ} \mathrm{C}$ was used in all measurements. The results are given as the z-average diameter (volume weighted diameter assuming spherical particles) and polydispersity index (measure for the relative width of the particle size distribution).

\section{Transmission electron microscopy(TEM)}

Freshly prepared DPPC liposomes and LEAA were after examined with transmission electron microscope JEOI- JEM 1230 electron microscope ( Jeol, Tokyo, Japan) using negative staining method . $10 \mu \mathrm{L}$ of liposome suspensions were applied on carbon stabilized copper grids and stained with an aqueous solution of ammonium molybdate $(1 \% \mathrm{w} / \mathrm{v})$ is used as staining agent followed by a 2-min wait at room temperature at $24^{\circ} \mathrm{C}$, removal of the excess solution with a filter paper . The morphology of LEAA was examined with TEM operating at 40 and $60 \mathrm{kV}$ and images were recorded with Bio scan CCD camera using digital Micrograph Software (Gatan Inc., Washington, USA).and compared to blank liposome.

FTIR SPECTROSCOPY. FTIR spectra of samples of DPPC liposomes deposited in $\mathrm{KBr}$ disks were recorded on a Jasco FT/IR 460 plus (Japan) spectrometer. For each sample the spectra were recorded 3 times from 4000 to $500 \mathrm{~cm}-1$.

Optical absorption spectra of Hemoglobin diluted with deionized water at room temperature ( $25 \pm 1^{\circ} \mathrm{C}$ ) on the base of heme absorption band at $576 \mathrm{~nm}=0.5$ was done through the use of the double beam UV -Vis spectrophotometer type Perkin Elemer precisely (Lambada 45) manufactured in Germany in the wavelength range from $250 \mathrm{~nm}$ to $700 \mathrm{~nm}$.
All viscosity measurements were carried out at a constant temperature of $25 \pm 1^{\circ} \mathrm{C}$ by the Ostwald capillary viscometer The measurements were performed at a certain hemoglobin concentration was adjusted by an appropriate dilution with deionized water at room temperature $\left(25 \pm 1^{\circ} \mathrm{C}\right)$ on the base of heme absorption band at $576 \mathrm{~nm}$ where the absorbance of $\mathrm{Hb}$ at $576 \mathrm{~nm}=0.5$. The results in the average of four reading.

The electrical conductivity was determined under constant temperature and concentration by using a conductivity meter type HI 8633, with a diptype cell which has fully protected electrodes made by Hanna instruments manufactured in Germany..The conductivity meter probe should be carefully washed with deionized water before each measurement. The results in the average of four reading.

\section{Results and Discussion}

\section{Particle size Distribution}

The size of the DPPC liposomes determined by dynamic light scattering method as a function of volume at $25{ }^{\circ} \mathrm{C}$ was $402.3 \mathrm{~nm}$ also the size of liposome encapsulation ascorbic acid(LEAA) was $421.6 \mathrm{~nm}$ shown in figure (1-a ) and figure (1-b) respectively. These result are in agreement with the previous studies by Wechtersbach et al. (2012) and more than the values obtained by Farhang et al. (2012) which indicated that LEAA diameter is of good evaluation in terms of safety and suitable to penetrate the cell membrane easily. Polydispersity index (PDI) effectively accounts for particle homogeneity of colloidal suspension. Results obtained showed that blank DPPC liposome and LEAA formulations displayed PDI to be 0.480 and 0.539 respectively indicating narrow and homogenous particle size distributions. which might be caused by the hydrolysis of ester bonds or oxidation of poly unsaturated acyl chains of lipid Vanaja et al. (2013).

\section{Encapsulation efficiency}

The EE\% of AA in liposomal systems was analyzed separately by centrifugation. Result was 23.33\% less than that obtained by Marsanasco et al. (2011) the difference in result may be related to small amount of DPPC liposome used and these results are related to the fact that AA is hydrophilic drug part of it is inside of the liposome and part of it is outside and both can act as antioxidants. 


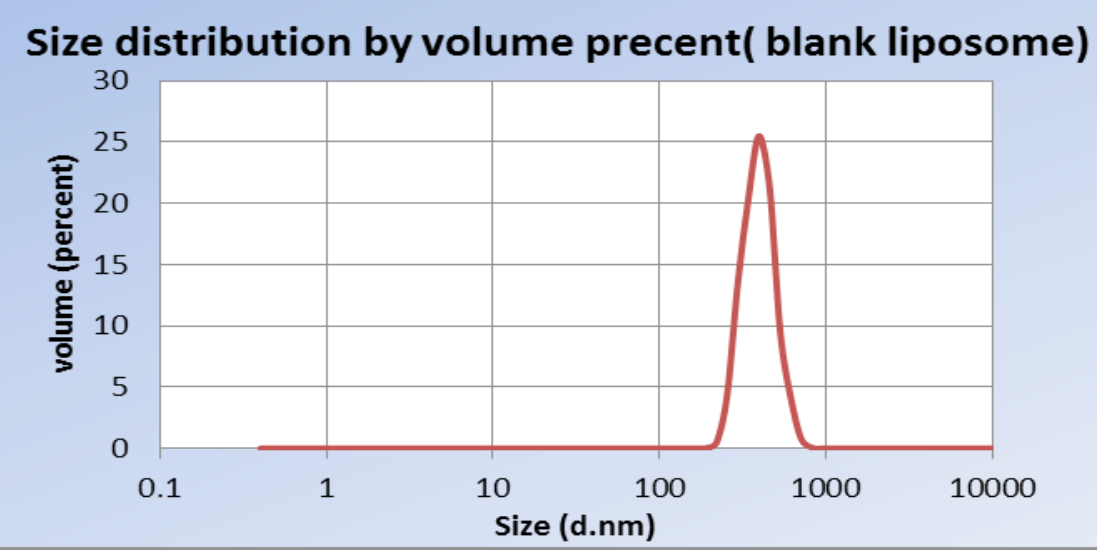

Fig.(1-a) : Size distribution of liposomes Of DPPC phospholipid solution.

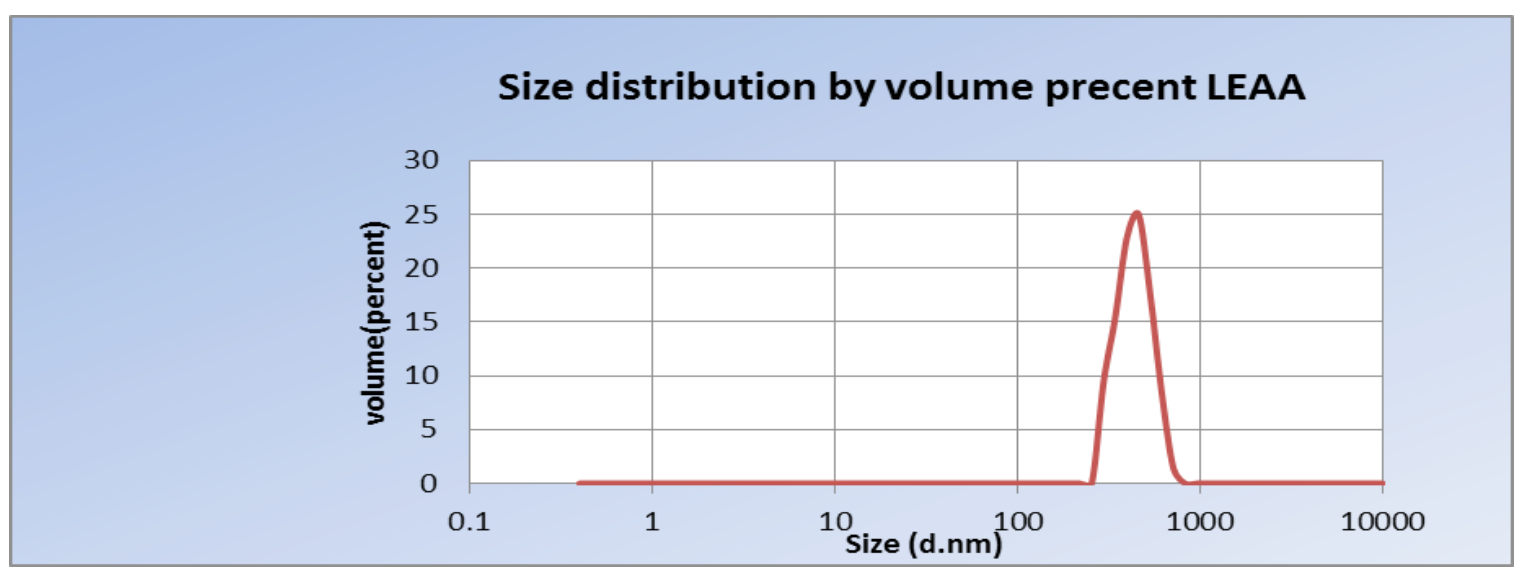

Fig.(1-b). Size distribution of liposomes encapsulation ascorbic acid 0f DPPC phospholipid solution .

Transmission electron microscopy

Surface morphological studies on the shape of prepared samples using transmission electron microscopy as shown in Fig (2-a) and Fig(2-b) Bar represents $500 \mathrm{~nm}$.

The result obtained from Transmission electron microscopy demonstrated that there are

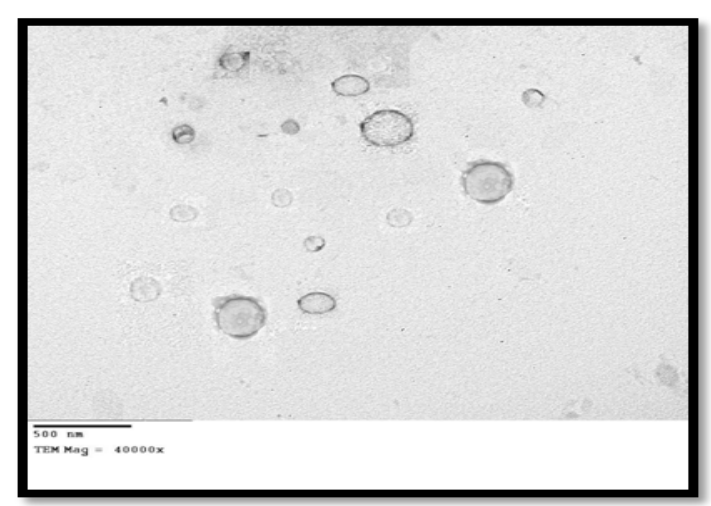

Fig.(2-a). TEM images for blank liposome shape and size.

Egypt. J. Biophys. Biomed. Eng., Vol. 19(2018 large unilamellar vesicles (LUVs) have a diameter in the range of 400-500 $\mathrm{nm}$ for all liposomes counted on TEM images as Wechtersbach . et al ,(2012) . but less than that obtaind by Ti Li ,et al. (2015) and Farhang, et al .(2012) .The difference in results may be due to the different conditions which are followed by previous authors. The morphology of all liposomes was nearly spherical

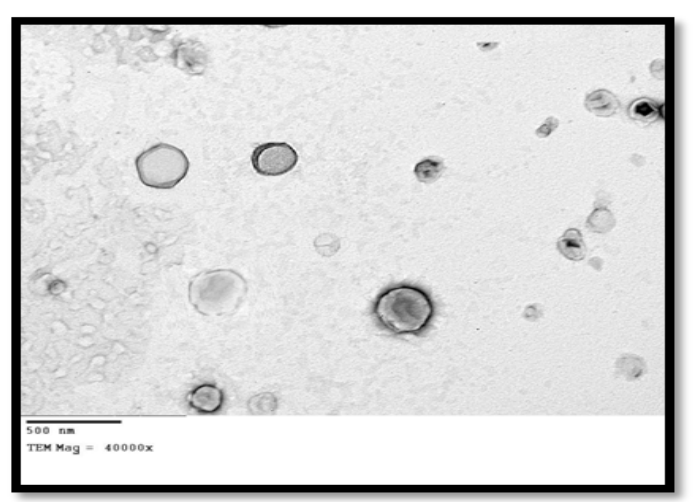

Fig.(2-b). TEM images for LEAA shape and size 
in shape with smooth surface, few aggregation and regular and relatively homogenous. There is no difference in morphology between the blank liposome and LEAA samples.

\section{FTIR spectroscopy}

FTIR was used, as a technique, to analyze possible changes in the structure of DPPC by analyzing the frequency of different functional groups and by investigating the acyl chains and head-group region of the lipid molecule in the presence or absence of ascorbic acid. The infrared spectra of membrane lipids can be separated to great advantage into spectral regions, which originate from molecular vibratin of the hydrophilic headgroup and theose of the hydrophobic hydrocarbon tail. The FTIR spectrum for DPPC blank liposome and liposome encapsulation ascorbic acid shown in Fig (3). It is noticed that there is no change in the wavenumber corresponding to acyl chain conformation at $3460 \mathrm{~cm}-1$.The position of the symmetric and asymmetric $\mathrm{CH} 2$ bands is hardly changed in the presence of ascorbic acid from (2853 to $2850 \mathrm{~cm}-1)$ and from (2924 to $2921 \mathrm{~cm}-1)$. In order to analyze the interaction of ascorbic acid with the glycerol backbone near the head group of the phospholipids, the $\mathrm{C}=\mathrm{O}$ stretching band at $1640 \mathrm{~cm}-1$ was analyzed. The characteristic lipid peak $\mathrm{C}=\mathrm{O}$ slightly shifted in the presence of ascorbic acid to lower frequency values $1637 \mathrm{~cm}-1$. The decrease in the frequency indicates a strengthening of the hydrogen bonds or even a formation of new hydrogen bonds between the components Korkmaz and Severcan, (2005). Also, the degree of hydrogen-bond formation was monitored in the glycerol backbone region of the DPPC molecule by changes in the contours of the ester $\mathrm{C}=\mathrm{O}$ stretching bands Blume et al. (1988).

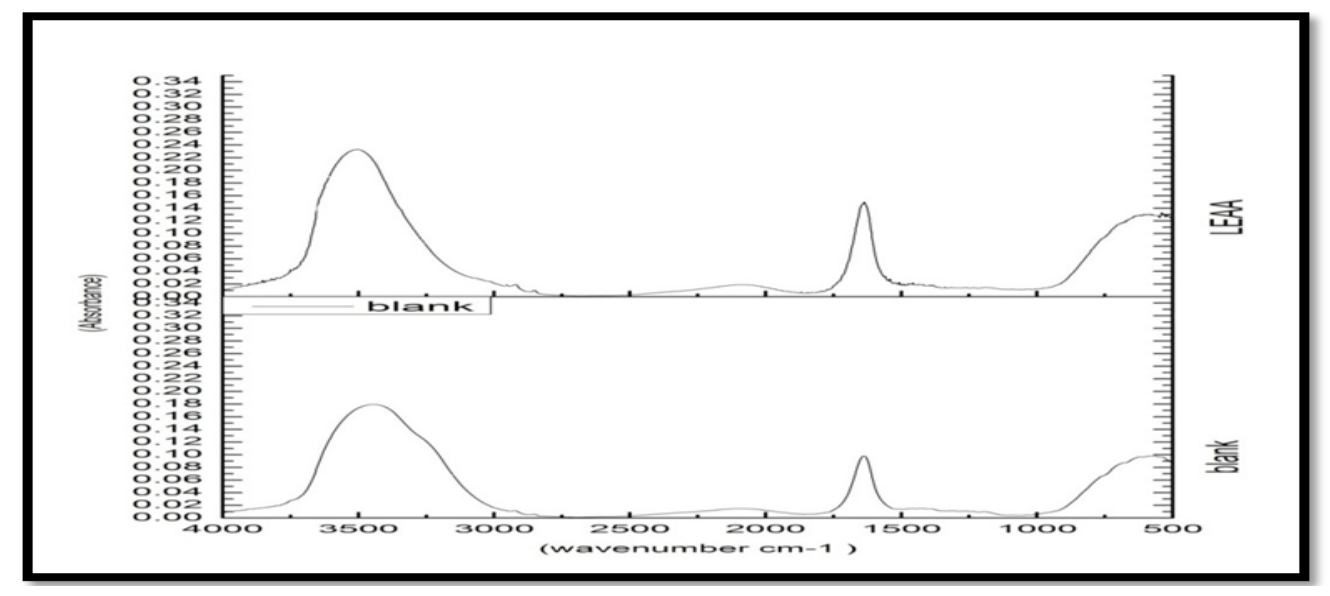

Fig. 3. Infrared spectra of aqueous dispersions of DPPC for blank liposome sample and liposome encapsulation ascorbic acid (LEAA).

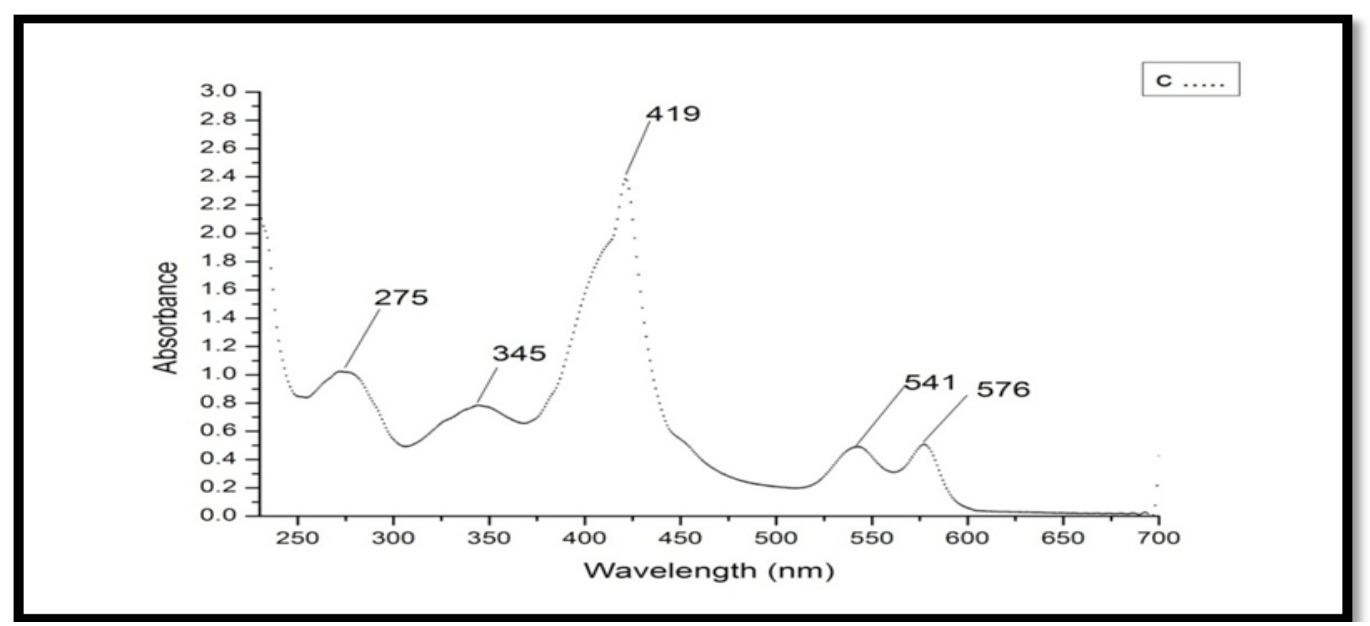

Fig. 4. Absorption spectrum of normal hemoglobin of control (Group C). 


\section{Absorption spectra of hemoglobin}

Absorption spectra of hemoglobin ( $\mathrm{Hb})$ extracted from control group $(\mathrm{C})$ are shown in Fig. 4 which characterize hemoglobin bands as follows: The globin band at the wavelength 275 nm which attributed to the aromatic amino acid chain, The globin - heme interaction band at (345) $\mathrm{nm}$ is due to the absorption by non-covalent bond between the iron and the histidine of the protein part,Soret band at (419) nm which is expressed as the characteristic peak of iron(iron band ligand), The band at (541) nm(Fe-N in porphyrine) which is attributed to nitrogen iron bonds in porphyrine rings, and Heme-heme interaction band at (576) $\mathrm{nm}$. These wavelengths are comparable with those found in literature HEMIDA et al. (2011).

Figures 5 show the Absorption spectra of hemoglobin exposed to $5 \mathrm{GY}$ of $\gamma$-irradiation with dose rate $62 \mathrm{c} \mathrm{GY/minute} \mathrm{group} \mathrm{(A),} \mathrm{irradiated}$ hemoglobin with liposome group $(\mathrm{E})$, and the control group (C).

Great difference is detected in the globin part , showed that the absorbance of aromatic amino acid band at (275 $\mathrm{nm})$ which increased for all blood exposed to $\gamma$-irradiation, increase in absorbance of globin -heme interaction band was observed compared to control this referred to the weakness of non-covalent bond between globin and heme-iron. Increase in the intensity of soret band was aslo detected. The ratio in the nitrogen ferric band(541 nm) and heme-heme interaction band $(576 \mathrm{~nm})$ showed adecrease in the ratio values than control .with the apperance of new band at $630 \mathrm{~nm}$ which indicates the convertion of a percintage of oxyHb to metHb Abd-Elmotaleb, (1992). These results indicate a partial loss of $\mathrm{Hb}$ molecule stability since Hemoglobin possesses an iron atom core in its ferrous $(\mathrm{Fe} 2++)$ state. If the iron is oxidized to its ferric $(\mathrm{Fe} 3++)$ state, its oxygen transport capabilities are diminished and the hemoglobin molecule is then called methemoglobin (metHb) MAY EID et al , (2011) .There is no detectable change is observed in absorption spectra for hemoglobin exposed to $\gamma$-irradiation subgroup (A) either before or after treating with liposome.

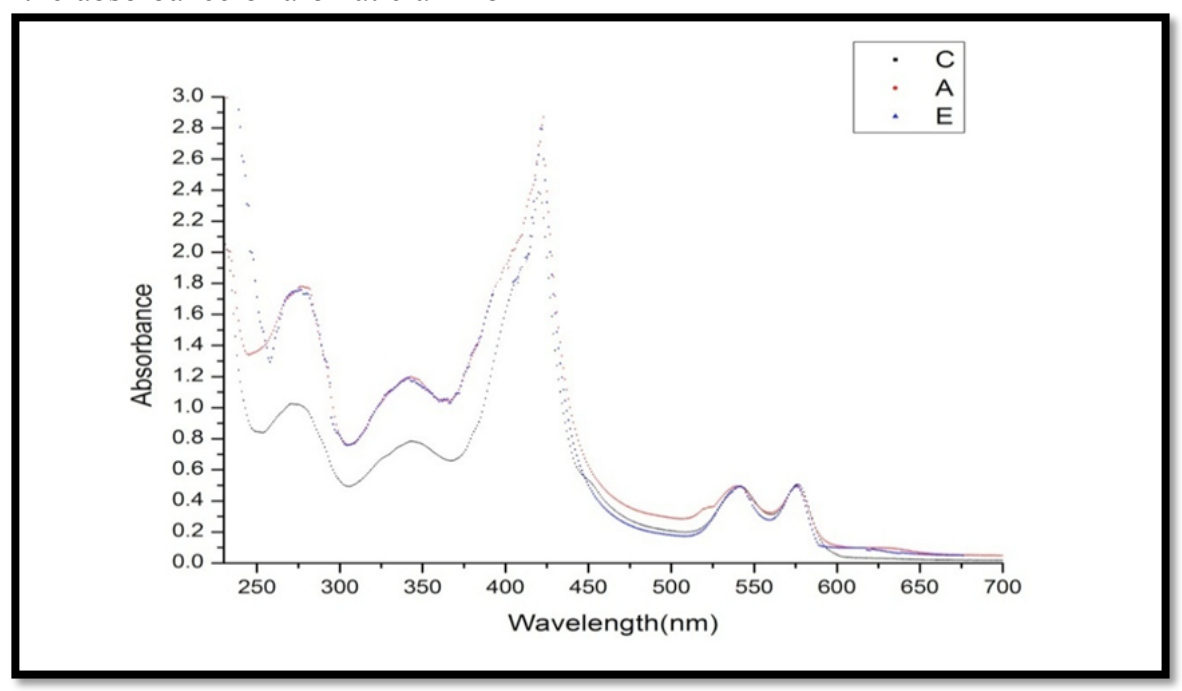

Fig. 5. The absorption spectra of $\mathrm{Hb}$ for control group(C), irradiated group (A) and irradiated $\mathrm{Hb}$ with liposome group (E) .

The absorption spectra of $\mathrm{Hb}$ extracted from blood of rats which exposed to $5 \mathrm{GY}$ of $\gamma-$ irradiation $62 \mathrm{cGY} / \mathrm{mint}$ group (A),blood with different dose of free AA $(20 \mu \mathrm{g} / \mathrm{ml}$ and $40 \mu \mathrm{g} /$ $\mathrm{ml}) 2 \mathrm{hr}$ before irradiation groups( B2 and,B3) respectively comparison with control one (C), as shown in Fig. 6 from the figure it was concluded that there is some repair for the damage caused by irradiation as shown in Table 1.
The absorption spectra of $\mathrm{Hb}$ extracted from blood of rats which exposed to $5 \mathrm{GY}$ of $\gamma$ irradiation $62 \mathrm{cGY} / \mathrm{mint}$ group (A),blood with different dose of LEAA $(20 \mu \mathrm{gLEAA} / \mathrm{ml}$ and $40 \mu \mathrm{gLEAA} / \mathrm{ml}$ ) $2 \mathrm{hr}$ before irradiation groups( D2 and,D3) respectively comparsion with control one (C), as shown in figure (7). From the figure it was concluded that there is more repair for the damage caused by irradiation as shown in Table 1 . 
TABLE 1. The Absorption spectra of hemoglobin extracted from blood of rats which exposed to 5 GY of $\gamma-$ irradiation group (A), irradiated $\mathrm{Hb}$ with liposome group group (E), subgroups having free AA (B2 and B3) and subgroups having LEAA (D2 and D3) compare with control groups (C).

\begin{tabular}{cccccccc}
\hline $\begin{array}{c}\text { Sample } \\
\text { group }\end{array}$ & $\begin{array}{c}\text { Aromatic } \\
\text { amino acid } \\
\lambda=\mathbf{2 7 5} \mathbf{~ n m}\end{array}$ & $\begin{array}{c}\text { Globin_heme } \\
\text { interaction } \\
\lambda=\mathbf{3 4 5} \mathbf{~ n m}\end{array}$ & $\begin{array}{c}\text { Soret } \\
\text { band(oxy } \\
\mathbf{H b}) \mathbf{\lambda = 4 1 9} \\
\mathbf{n m}\end{array}$ & $\begin{array}{c}\text { Nitrogen_ } \\
\text { iron band } \\
\lambda=\mathbf{5 4 1} \mathbf{~ n m}\end{array}$ & $\begin{array}{c}\text { Heme- } \\
\text { heme } \\
\text { interaction } \\
\boldsymbol{\lambda}=\mathbf{5 7 6 n m}\end{array}$ & $\begin{array}{c}\mathbf{5 7 6 / 5 4 1} \\
\text { ratio }\end{array}$ & $\begin{array}{c}\text { met Hb } \\
\boldsymbol{\lambda}=\mathbf{6 3 0} \mathbf{~ n m}\end{array}$ \\
\hline C & 1.033 & .79950 & 2.4636 & 0.4907 & 0.5139 & 1.044 & 0.025 \\
A & 1.7597 & 1.2027 & 2.8166 & 0.4951 & 0.4917 & 0.993 & 0.096 \\
E & 1.7578 & 1.1890 & 2.7932 & 0.4940 & 0.49901 & 1.01 & 0.081 \\
B2 & 1.578 & 1.087 & 2.7447 & 0.5111 & 0.5213 & 1.02 & 0.057 \\
B3 & 1.4766 & 1.026 & 2.623 & 0.5182 & 0.5305 & 1.023 & 0.0408 \\
D2 & 1.2575 & 1.031 & 2.583 & 0.4677 & 0.4823 & 1.031 & 0.0396 \\
D3 & 1.1961 & 0.864 & 2.545 & 0.4816 & 0.4981 & 1.034 & 0.0451 \\
\hline
\end{tabular}

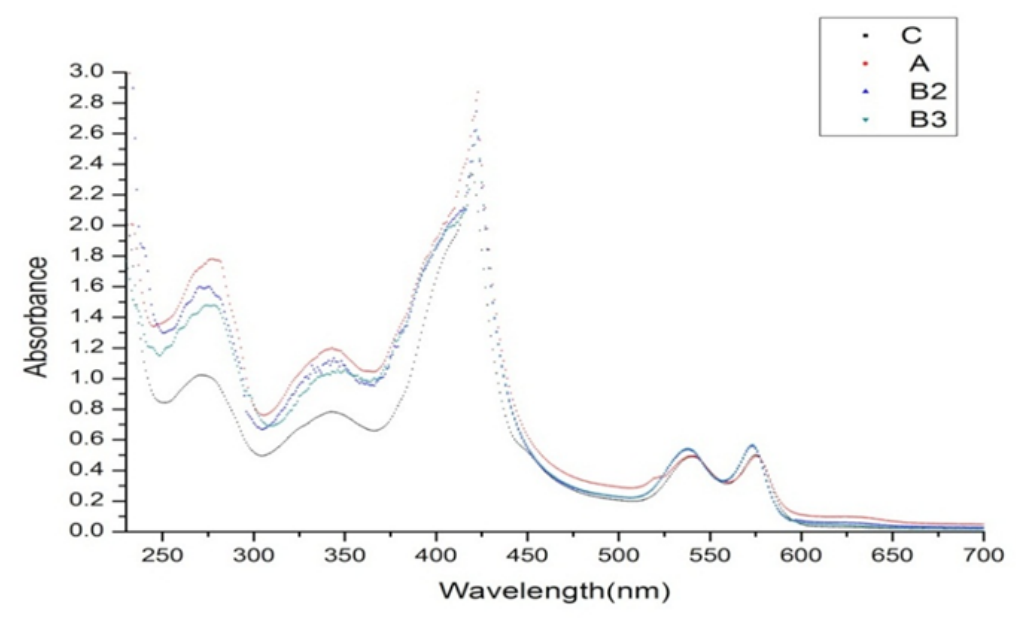

Fig. 6. The absorption spectra of $\mathrm{Hb}$ extracted from blood of rats control group (C),irradiated group (A) and $\mathrm{Hb}$ with two dose of free AA $(20 \mu \mathrm{g} / \mathrm{ml}$ and $40 \mu \mathrm{g} / \mathrm{ml}) 2 \mathrm{hr}$ before irradiation groups( B2 and,B3) respectively.

Figure7 The absorption spectra of $\mathrm{Hb}$ extracted from blood of rats control group (C),irradiated group (A) and $\mathrm{Hb}$ with two dose of LEAA (20 $\mu \mathrm{gLEAA} / \mathrm{ml}$ and $40 \mu \mathrm{gLEAA} / \mathrm{ml}) 2 \mathrm{hr}$ before irradiation groups( D2 and D3) respectively .

Irradiation disrupted the heme groups, resulting in increase of the absorbance at sort band. It causes a slight breakdown of the polypeptide chain break covalent bonds and disrupts the ordered structure of proteins as a result of the increase in the free radical production (reactive oxygen species) These free radicals contribute to hemoglobin denaturation, In the presence of ascorbic acid a protective effect against $\gamma$-irradiation damage and LEAA are observed. This finding is achieved by the studied parameters given in the table for the investigated blood treated with both doses of ascorbic acid $20 \mu \mathrm{g} / \mathrm{ml}$ and $40 \mu \mathrm{g} / \mathrm{ml} 2 \mathrm{hr}$ before exposing to $\gamma$-irradiation (B2, B3)groups. These parameters are found to become closer to those given of the control group (c). Ascorbic acid acts as direct free radical scavenger and detoxifies the highly cytotoxic $\mathrm{OH} \cdot$ radical and other radicals produced by ionizing radiation. Because of its rather small size and high solubility, ascorbic 
acid crosses biological membranes easily, thus reaching all compartments in the cell, when ascorbic acid is placed inside DPPC liposome which kept ascorbic acid from oxidation and make it enter biological membrane more easily, which enhances the protection of the cell membrane from ionizing radiation so blood treated with both doses of LEAA $20 \mu \mathrm{gLEAA} / \mathrm{ml}$ and $40 \mu \mathrm{gLEAA} /$ $\mathrm{ml} 2 \mathrm{hr}$ before exposing to $\gamma$-irradiation (D2, D3) groups is protected from the damaging effect of ionizing radiation. These parameters are found to become MORE closer to those given of the control group (c).

\section{Relative viscosity of hemoglobin}

The Relative viscosity $(\eta)$ of hemoglobin extracted from animals of different subgroups is measured at constant concentration where absorbance of $\mathrm{Hb}$ at $576 \mathrm{~nm}=0.5$, and temperature $\left(25 \pm 1^{\circ} \mathrm{C}\right)$. The values in the average of four measurements are show in Fig. 8.

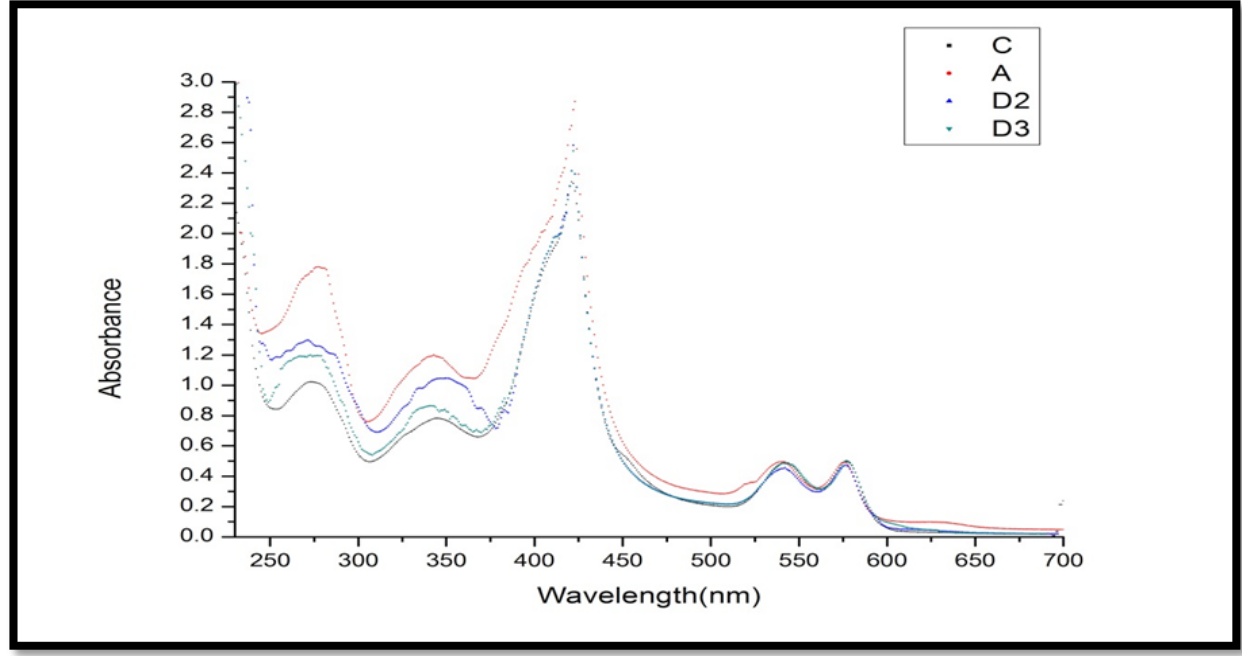

Fig. 7. The absorption spectra of $\mathrm{Hb}$ extracted from blood of rats control group (C),irradiated group (A) and $\mathrm{Hb}$ with two dose of LEAA $(20 \mu \mathrm{gLEAA} / \mathrm{ml}$ and $40 \mu \mathrm{gLEAA} / \mathrm{ml}) 2 \mathrm{hr}$ before irradiation groups( D2 and $\mathrm{D3}$ ) respectively .

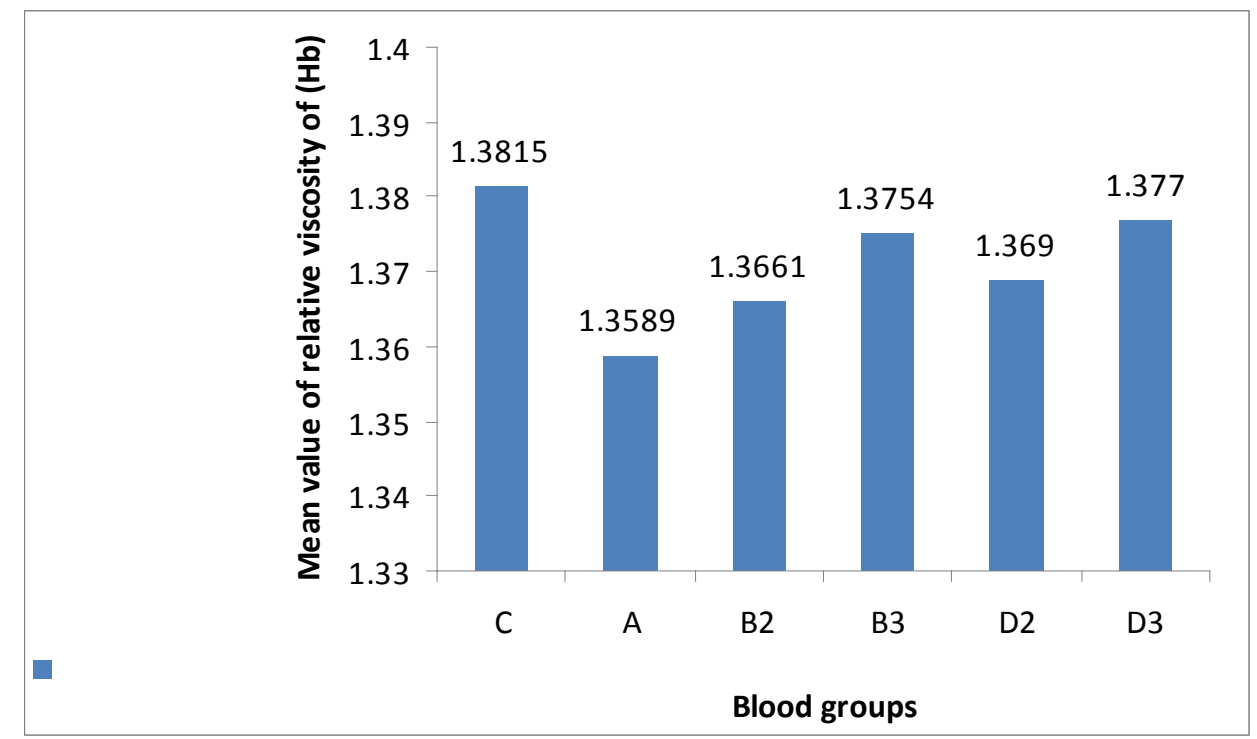

Fig. 8. Histogram of the relative viscosity of $\mathrm{Hb}$ for control(C), irradiated groups $(\mathrm{A})$, subgroups $(\mathrm{B} 2, \mathrm{~B} 3)$ and subgroups(D2,D3). 
These values indicate that there is a slight decrease in the Relative viscosity for hemoglobin of group exposed to $\gamma$-irradiation (A) as it compared with control group $(\mathrm{C})$. The decrease in viscosity detected by exposing to $\gamma$-irradiation (even if it is very small) indicates some changes in dimension and shape of hemoglobin molecule SAAD et al. (1996). By treating with free ascorbic acid (B2 and B3) subgroups, the viscosity values become closer to those of control group (C), and in the presence of LEAA (D2 and D3)subgroups the value of Relative viscosity came closer to control group $(C)$ sence the liposome mantaine the relase of ascorbic acid and keep it for a long time.

\section{Electrical conductivity of hemoglobin}

The electrical conductivity $((\sigma))$ of hemoglobin extracted from blood of different subgroups is measured at certain concentration where absorbance of $\mathrm{Hb}$ at $576 \mathrm{~nm}=0.5$, and constant temperature $\left(25 \pm 1^{\circ} \mathrm{C}\right)$ The value in the average of four measurement are illustrated in Fig.9 .

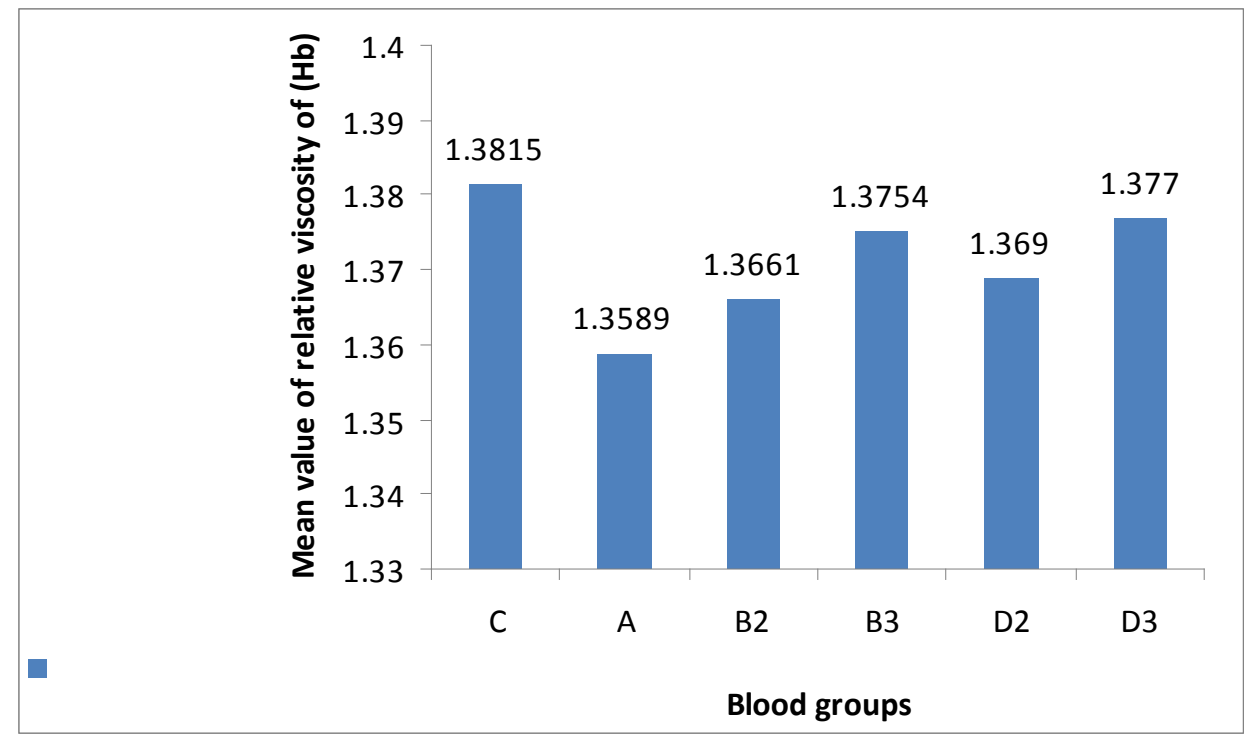

Fig. 8. Histogram of the relative viscosity of $\mathrm{Hb}$ for control(C), irradiated groups (A), subgroups (B2,B3) and subgroups(D2,D3).

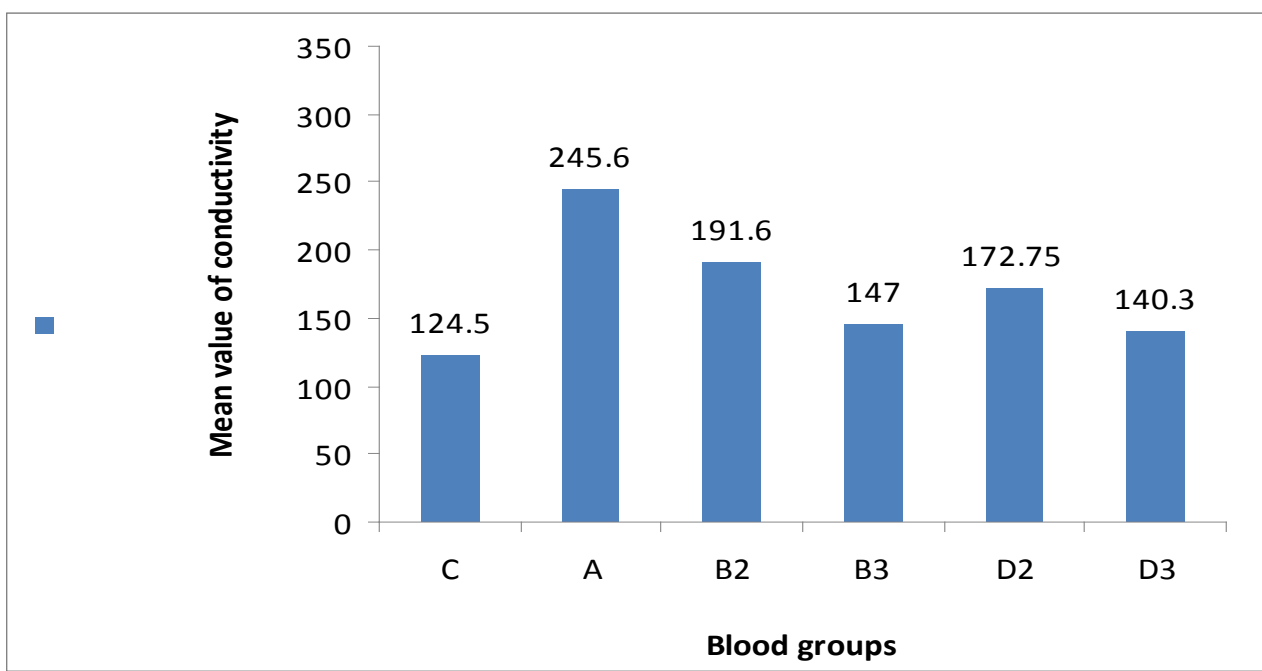

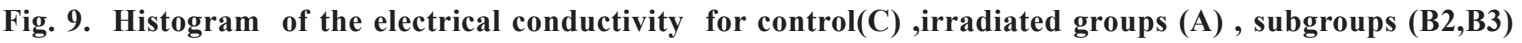
and subgroups(D2,D3). 
It is noticed that there is some increase in the conductivity of group (A) as compared with those of control group (C). This could be a good evidence for the increase of free radicals which are expected to be formed by exposing to $\gamma$-irradiation HEMIDA et al. (2011).By treating with free ascorbic acid subgroups(B2 and B3) all these values become closer to those of control group (C), as the ascorbic acid act as scavenger free radical formed Niki, (1991) \& Frei et al. (1989). but in the presence of LEAA (D2 and D3) subgroups the value of electrical conductivity came more closer to control group (C) since the liposome maintained the release of ascorbic acid and keep it for along time mixed with hemoglobin.

\section{Conclusion}

The results of TEM, DLS and FTIR spectroscopy measurements indicate that ascorbic acid interacts with the phospholipid surface and the lipophilic core of the liposomes bilayers. The encapsulation of DPPC liposomes with ascorbic acid led to an improvement in the stability of lipid vesicles. These results shed light on the mechanism of interaction of ascorbic acid with lipids either in natural tissues or in artificial drug delivery systems. Appropriate combinations of the liposomal and ascorbic acid characteristics may produce liposomes with specific, prolonged, and controlled release. The results indicate that a lipid-ascorbic acid complex might be used either in cosmetology or in pharmacology as an effective drug delivery system.

Exposing hemoglobin to gamma irradiation causes disruption in the heme groups, slight breakdown of the polypeptide chain and break covalent bond this leading to the change in the biophysical and biochemical properties which are expected to happen under the effect of the ionizing radiation. These changes were studied through UV absorption spectra, electric conductivity and viscosity measurements. A pronounced increase in the absorbance of aromatic amino acid band ,globin -heme interaction band which refer to the weakness of non-covalent bond between globin and heme-iron , absorption ratio A576 / A541 was decreased than the control one and it is noticed a formation of a new band at $630 \mathrm{~nm}$ which indicates the conversion of a percentage of oxyHb to metHb which indicated a partial loss of $\mathrm{Hb}$ molecule stability. These changes were also studied through the increase in the conductivity parameters and decrease in the viscosity measurements after exposing to gamma Egypt. J. Biophys. Biomed. Eng., Vol. 19(2018 irradiation. The changes which are obtained as a result of exposing to gamma irradiation are found to be decreased by treating with ascorbic acid and more decreased with liposome encapsulation ascorbic acid .This due to the rate of release of ascorbic acid keeping it for longer time mixed with the hemoglobin .

\section{References}

1. Abd-Elmotaleb, S.A. (1992) Thesis of Photobiophysical studies on the effect of near and far UV-irradiation on hemoprotein structure and function, p.26, 27, 82, 83, 90 .

2. Blume, A.; Hu"bner, W.; and Messner, G. (1988) Fourier transform infrared spectroscopy of 13COlabeled phospholipids. Hydrogen bonding to carbonyl groups. Biochemistry 27, 8239-8249.

3. Duschesne, J., Gilles, R. and Mosora, F. (1975) Effect of antioxidant substances on the level of free organic radicals naturally present in the rat diaphragm. C R Acad Sci. (Paris ), 281, 945-945.

4. Farhang, B.; Kakuda.Y. and Corredig, M. (2012) Encapsulation of ascorbic acid in liposomes prepared with milk fat globule membrane-derived phospholipids. Dairy Sci. \& Technol. 92,353-366.

5. Frei, B.; England , L.; Ames, B. (1989) Ascorbate is an outstanding antioxidant in human blood plasma. Proc Natl Acad Sci USA. 86, 6377-81.

6. Hall, E.J. (2000) Radiobiology for radiobiologist. 5th Edition. Philadelphia: Lippincott Williams \& Wilkins.

7. Hemida, Sh.F.; Abd El Nour, K.N.; Farag, H.I.; Abouaiad,T.H. and Alrouby,M. (2011) Protective Effect Of Melatonin Onhemoglobin Damage Induced By Gamma Irradiation Romanian $J$. Biophys., Vol. 21, No. 4, P. 317-329, Bucharest.

8. Imlay, J.A.; Linn, S. (1988) DNA damage and oxygen radical toxicity. Jun 3; 240(4857):1302 in vitro digestion. Food Research International, 48(2), 499-506.

9. Jagetia, G. C. (2004) Ascorbic acid treatment reduces the radiation induced delay in the skin excision wound of Swiss albino mice. Indian $J$ Radiat Res. 1,7-7.

10. Kall, M.A. and Andersen, C. (1999) Improved method for simultaneous determination of ascorbic acid and dehydroascorbic acid, isoascorbic acid and dehydroisoascorbic acid in food and biological samples. J Chromatogr B Biomed ;730(1),101-11. 
11. Korkmaz, F.; and Severcan , F. (2005) Effect of progesterone on DPPC membrane: evidence for lateral phase separation and inverse action in lipid dynamics. Arch Biochem Biophys 440,141-147.

12. Laverne ,J.A .(2000 )OH radicals and oxidizing products in the gamma radiolysis of water. Radiat Res;153(2),196-200.

13. Li, uW. L.; Ye, A.; Liu, W.; Liu, C. M.; a nd Singh, H. (2013) Structure and integrity of liposomes prepared from milk- or soybean-derived phospholipids during Lipids 96,141-157.

14. Mallikarjuna Rao, K. V. N.; and Jagetia, G. C, (2004) Ascorbic acid treatment enhances the wound healing in mice exposed to radiation. Indian $J$ Radiat Res. 1, 24-24.

15. Marsanasco, M.; Márquez, A.L.; Wagner ,J.R.; Alonso, S.DV. and Chiaramoni, N.S.(2011) Liposomes as vehicles for vitamins $\mathrm{E}$ and $\mathrm{C}$ : An alternative to fortify orange juice and offer vitamin C protection after heat treatment. J. Food Research International 44, 3039-3046.

16. May Eid.;Gamal El Bahy, A.; And Shabaka . (2011):Spectroscopic Study Of The Effect Of Alpha Tocopherol On Erythrocytes Irradiated With Neutrons Romanian J. Biophys., Vol. 21, No. 4, P. 303-316, BUCHAREST,

17. Niki, E. (1991)Action of ascorbic acid as a scavenger of active and stable oxygen radicals. $\mathrm{Am}$ J Clin Nutr. 54,1119s-24s.

18. Saad, A.; El Din,A.; Desouky,O.S.; El Behay,A.Z.; And El Sayed,A.A. (1996) High temperature radiation-induced reduction of No, Radiat. Phys. Chem., 48(5), 755-757.

19. Silva ,R.; Ferreira,H.; Little ,C. and CavacoPaulo,A (2010) Effect of ultrasound parameters for unilamellar liposome preparation Ultrasonics
Sonochemistry 17 . 628-632.

20. Steel,G .G.( 2002) Basic clinical radiobiology.3th Edition. USA: CRC Press .

21. Ti Li1; Shuibing Yang ;Wei Liu ;Chengmei Liu ; Weilin Liu ;Huijuan Zheng;Wei Zhou and Guihong Tong ;(2015)Preparation and Characterization of Nanoscale Complex_Liposomes Containing Medium-Chain Acids and Vitamin C International Journal of Food Properties, 18,113-124Fatty.

22. Trivelli, L.A.; Ranney, H. M.; and Lai, H. T. (1971) Hemoglobin components in patients with diabetes mellitus. N. Eng. J. Med., 284, 353-362.

23. Vanaja ,K. ; Wahl,M.A.; Bukarica,L.; and Heinle,H . (2013) Liposomes as carriers of the lipid soluble antioxidant resveratrol: Evaluation of amelioration of oxidative stress by additional antioxidant vitamin . Life Sciences journal homepage: www.elsevier. com/locate/lifescie

24. Vanaja, K.; Shobha Rani, R.H . and Sacchidananda , S.(2008) Formulation And Clinical Evaluation Of Ultradeformable Liposomes In The Topical Treatment Of Psoriasis. Clinical Research and Regulatory Affairs, 25(1),41-52.

25. Wechtersbach,L.; Ulrih,N.P.; and Cigi,B.(2012) Liposomal stabilization of ascorbic acid in model systems and in food matrices Food Science and Technology $45,43.49$.

26. Wilson, R.L. (1983) Free radical repair mechanisms and the interaction of glutathion and vitamin $\mathrm{C}$ and E. In: Radioprotectors and anticarcinogens, eds. Nyga, O.F.and Simic, M.G.

(Received 23/3 / 2018; accpted 23 / 4 / 2018 ) 
دور الليبوزومات المحمله بحمض الاسكوربيك علي الضرر الذي يلحق بالهيموجلوبين عند

تعرضه لاشععه جاما

عايده عبد الكريم سلامه * ، محمد حسنيين جابر* ،عزيزه عبد المنعم السعيد ** ، بسمه يوسف السيا

* العدوي عالده ع

** ـ ققم الفيزياء ـ كلية العلوم - جامعة الازهر (فرع البنات) *قو قسم الفيزياء الحيوية ـ كلية العلوم - جامعة

تسبب الإشعاعات المؤينة تلفًا خطيرًا في النظام البيولوجي ـ يتم استخدام بعض الأدوية ومضادات الاكسده لمنع هذا

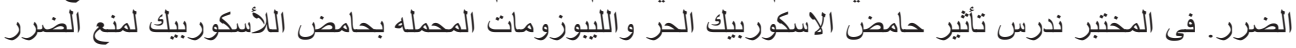

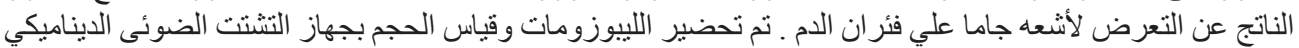

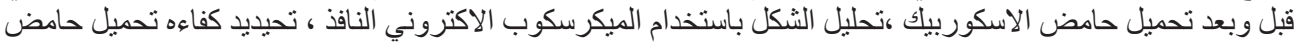

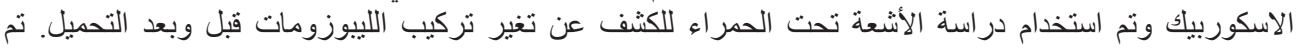

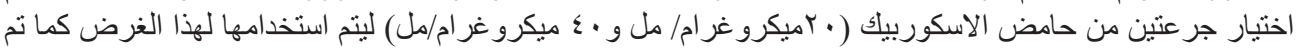

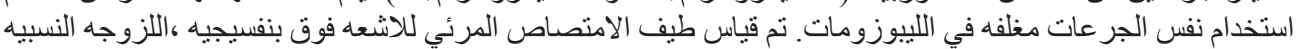

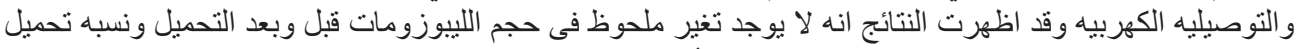

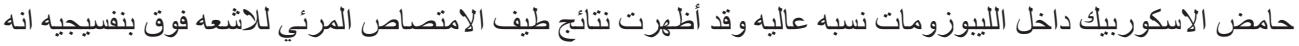

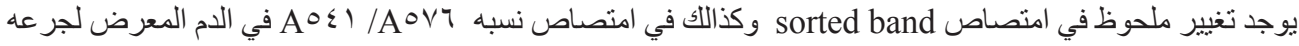
هر من اشعه جاما بمعدل GY o

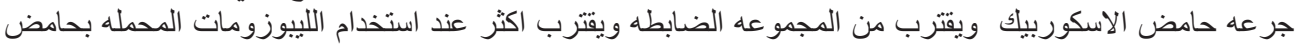

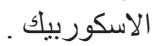

